\title{
Task Dependent Variations of Ocular Lateropulsion in Wallenberg's Syndrome
}

\author{
T.H. KIRKHAM, D. GUITTON and M. GANS
}

SUMMARY: The eye movements of a patient with a lefi lateral medullary infarct (Wallenberg's syndrome) were recorded using the scleral search coil in magnetic field technique. When asked to look at spontaneously appearing targets, saccades to the left were generally accurate but those to the right reached the target by multiple step refixation sac'ades. Large amplitude rightward saccades were possible herween two continuously visible targets or when making voluntary sac'cades in the dark.

Vertical saccades, up or down, between spontaneously appearing targets were always associated with a leftward eye movement (lateropulsion). Voluntary ver-

RÉSUMÉ: Les mowements oculaires d'un patient souffrant du syndrome de Wallenberg du 'ôté gauche ont été enregistrés en utilisant la technique de la bobine sclérale soumise à un champ magnétique. Trois conditions expérimentales ont été réalisées. D'abord le patient faisait les saccades entre les cibles qui paraissaient spontanément dans le champ, visuel. Les saccade's vers la gauche étaient normales tandis que celles vers la droite étaient hypométriques. Les saccades verticales, vers le haut ou vers le has étaient toujours accompagnées d"un mouvement anormal rapide vers la gauche, soit une latéropulsion. Deuxièmement, le patient faisait les saccades entre deux cibles continuellement illuminées. Les saccades horizontales étaient normales, les saccades tical saccades between continuously' visible targets showed that upward movements had left lateropulsion but downward movements were normal. Vertical voluntary saccades in the dark were oblique, upward saccades showing left lateropulsion and downward saccades showing rightward deviation. The aberrant horizontal components of vertical saccades had amplitude and velocity characteristics for components of normal oblique saccades. Possibly impaired assessment of verticality with incorrect eye position information produced by the infarct accounts for the lateropulsion of sac'ades in Wallenberg's syndrome.

vers le haut avaient une latéropulsion vers la gauche mais les saccades vers le bas étaient normales. Finalement, le patient exécutait des saccades volontaires dans l'obscurité sans cible. Encore les mouvements horizontaux étaient normaux, mais les saccades vers le haut étaient déviées vers la gauche et celles vers le has étaient déviées vers la droite. le mouvement résultant surle plan vertical était oblique.

Les mouvements anormaux de latéropulsion semblaient être des composants de saccades obliques normales. La latéropulsion s'explique peut-être par une incapacité de juger correctement la verticale, où en plus d'une déficience dans le traitement d'informations qui donne la position précise de l'oeil dans l'orbite.

\section{INTRODUCTION}

Lateral medullary infarcts produce a constellation of deficits, often called Wallenberg's syndrome, predominant among which are nausea, vomiting, hiccups, dysphonia, dysphagia, Horner's syndrome contralateral bodily sensory deficits, ipsilateral facial sensory defect, ipsilateral dysmetria, nystagmus and ataxia (Fisher et al, 1961; Currier, 1969). There is lateropulsion, an involuntary veering towards the affected side during movements. In the acute phase there is a tendency to fall or to sit tilted towards the side of the lesion. Some patients report pronounced subjective tilt of the environment (Möberg et al, 1962; Bjerver and Silfverskiöld, 1968; Kommerell and Hoyt, 1973; Hönsten, 1974). Subjective bodily lateropulsion tends to persist indefinitely.

Wallenberg's syndrome is often associated with more widespread vertebro-basilar insufficiency rather than the classical assumed occlusion of the posterior inferior cerebellar artery and there is thus some variation in the clinical picture and the autopsy findings (Fisher et al, 1961; Gillilan, 1964). Visual and ocular motor disturbances occur frequently because the infarct involves the vestibular nuclear and cerebellar brain stem connections involved in eye movement control. Some of the visual symptoms may result from disruption of input or output pathways of the inferior olive with consequent defective coordination of retinal and vestibular information (Hoyt and Frisen, 1975). Nystagmus has been almost universally reported, usually horizontal, often with a rotatory component, often differing on gaze right or left, sometimes vertical and exceptionally involving the eyelids (Daroff et al, 1968). Skew deviation, a vertical divergence of the 
eyes not explicable on the basis of a peripheral nerve lesion, with diplopia is often remarked. Lateropulsion of gaze occurs towards the side of the lesion (Kommerell and Hoyt, 1973; Hörnsten 1974 a, b; Collard et al, 1975; Hamann, 1979). The eyes may be permanently deviated away from the primary position (Collard et al, 1975) or the deviation may only be present when the eyes are closed (Möberg et al, 1962; Hörnsten, 1974; Hamann, 1979).

Kommerell and Hoyt (1973) recorded the eye movements of a patient with a left Wallenberg's syndrome. They observed bias of the eyes to the left side, all saccades to the left being hypermetric while those to the right were hypometric. Upward and downward saccades veered obliquely to the left and the eyes then reached the target by a series of corrective hypometric saccades to the right. Rightward saccades between two targets were hypometric but their patient could execute large amplitude saccades in a single sweep in contour free surroundings. In the present study we examined this task dependent oculomotor deficit. We also wished to determine whether the aberrent leftward horizontal deviation which occurred during vertical saccades was the horizontal component of a normal oblique saccade rather than a rapid horizontal displacement having an abnormal time course incompatible with that of a normal oblique saccade.

\section{MATERIAL AND METHODS}

\section{Case Report}

A 68 year old normotensive, diabetic male awoke with signs and symptoms compatible with a left lateral medullary infarct. He complained of nausea, hiccups, dysphagia, dysphonia, severe vertical oscillopsia, diplopia, left sided facial pain and pronounced ataxia, falling to the left when standing or sitting. Examination showed decreased left facial sensation to pin prick with absent corneal reflex, loss of pain and temperature sensibility of the right limbs, some dysmetria of left limbs and truncal and gait ataxia to the left, left Horner's syndrome and diminished left gag reflex. Limb stretch reflexes were normal with flexor plantar responses.

Visual acuity, fields and fundi were normal. Pursuit was a little jerky both horizontally and vertically. Primary position right beating nystagmus was present with horizontal gaze nystagmus whose amplitude was greater on right than left gaze. Saccades to the right were hypometric but were hypermetric to the left. Vertical saccades clearly deviated to the left particularly on upward gaze. He had a right fourth nerve palsy, the deviation measuring 0,6 and 10 diopters of right hypertropia on right, center and left gaze respectively. He kept his head tilted to the left where there was no vertical deviation but on right head tilt there were 12 diopters of right hypertropia.

The primary position nystagmus could no longer be seen by day 5 , the pursuit defect, horizontal gaze nystagmus and the hypermetric leftward saccades could not be detected by day 10 and the right fourth nerve palsy was no longer present 15 days after the infarct.

\section{Eye Movement Recording Methodology}

The eye movements from the left eye were recorded 12 and 20 days post infarct using the scleral search coil in magnetic field technique (Robinson, 1963; Collewijn et al, 1975). This method is excellent for the study of vertical eye movements being free of the distortions to which electrooculography is subject (Barre and Jones, 1965). In conjunction with our electronic circuitry, measurements of eye position could be made with an accuracy of up to 15 minutes of arc and with a band width of $0-1000 \mathrm{~Hz}(3 \mathrm{~dB})$. Records of eye position were displayed on paper using a Mingograf Siemens ink jet recorder ( $1 \mathrm{~K} \mathrm{~Hz}, 3 \mathrm{~dB})$ and were also photographed directly from an oscilloscope in the $X-Y$ mode. The head was held vertical and the right eye was occluded throughout the tests.

Saccades from Center to an Immediately Appearing Target.

Red, wide angled light emitting diodes (LED's) inserted into a flat black painted board served as targets. The LED's were positioned at $5^{\circ}$ intervals horizontally and vertically with respect to a central LED level with and $69 \mathrm{~cm}$ from the left eye. The central LED remained lit until the desired LED target was illuminated. Eye movements were calibrated by asking the subject to look from the central LED to other LED's at the beginning of each recording session.

\section{Voluntary Saccades Between Two Targets}

The two LED's $30^{\circ}$ eccentric right and left were continuously lit and the patient was asked to make repeated $60^{\circ}$ saccades between them. Vertically he made $50^{\circ}$ saccades from $30^{\circ}$ up to $20^{\circ}$ down.
Voluntary Saccades in the Dark

The room was in total darkness except for the center LED. This LED was then turned off and the patient was asked to maintain his gaze in the primary position and was then instructed to make eye movements of about $60^{\circ}$ horizontally or $50^{\circ}$ vertically based on his previous experience.

\section{Pursuit}

The subject sat $33 \mathrm{~cm}$ from an opaque screen. A high brightness monitor oscilloscope beam (Tektronix 608) was projected through a set of lenses to focus a spot on the screen at the level of the eyes. A wave form generator drove the oscilloscope to perform constant velocity trajectories extending 14 degrees to either side of or above and below the central position.

\section{RESULTS}

No differences were detected between the two recording sessions showing that the right fourth nerve palsy, which disappeared completely between the two sessions, had no effect on the results recorded from the left eye.

\section{Saccades from Center to an Immediately Appearing Target}

The tracings confirmed the clinical impression that the leftward hypermetric saccades, initially present, had resolved. Some $70 \%$ of leftward saccades undershot the target and required one small corrective saccade (fig. 1). The eye remained precisely on the target with no nystagmus. This was true for saccades commencing from right gaze to center as well as for saccades from center to left.

Rightward saccades always undershot the target whether they started from left gaze to the midline or from the midline to right gaze (fig. 1). They reached the target by multiple step refixation saccades (Bahill and Troost, 1979). On right gaze there was a nystagmus to the right of $1^{\circ}$ amplitude. There was less than a $200 \mathrm{msec}$. delay between each segment of the multiple step movement. There was no significant associated vertical eye movement during horizontal saccades (fig. 1).

Upward saccades significantly undershot the target (fig. 2) and a number of smaller saccades were necessary to place the eye on target when fixation was stable without 


$$
\left[5^{\circ}\right.
$$

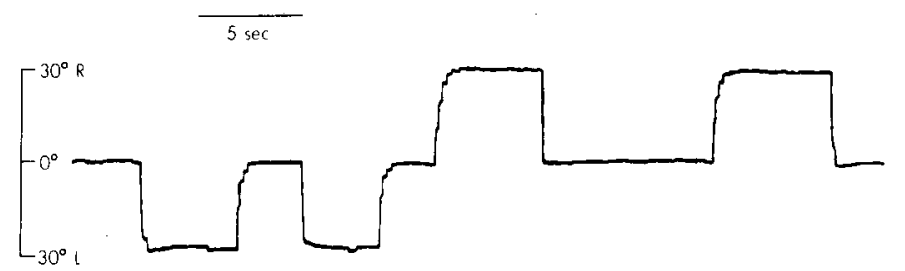

Figure $l$ - Horizontal movements made towards spontaneously appearing targets. All rightward saccades are hypometric. Leftward saccades are generally accurate. No vertical movement occurs during horizontal saccades. Upper trace: vertical movements. Lower trace: horizontal movements.

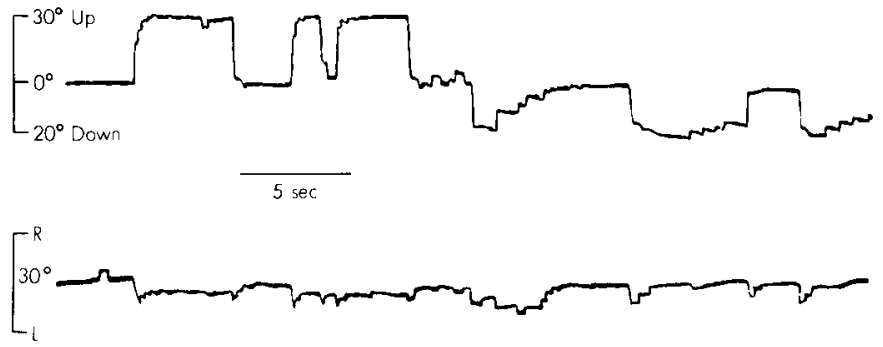

Figure 2 - Vertical saccades, whether up or down (upper trace), made between spontaneously appearing targets are always associated with a leftward deflection of the eyes (lower trace) which is corrected by a staircase of rightward saccades. nystagmus. This occurred on saccades from down gaze up to the midposition and from the midposition to up gaze. Downward saccades from upgaze to midposition showed usually one hypometric step and then the target was accurately fixated. Saccades from

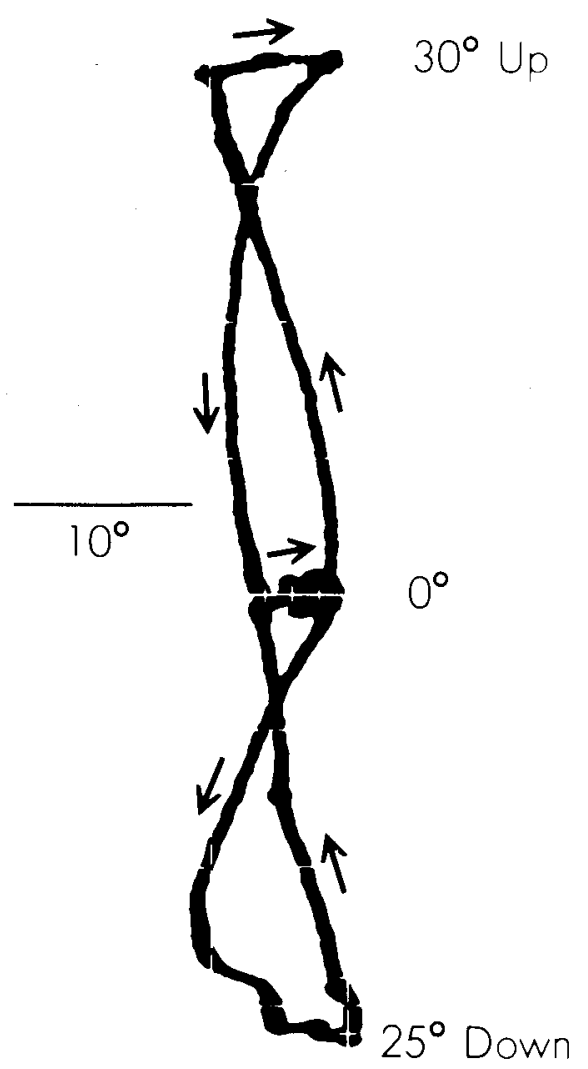

Figure 3 - X-Y plot of vertical saccades from midposition $\left(0^{\circ}\right)$ show a leftward deflection corrected by small rightward saccades. Arrows show the direction of the saccades. midposition to downgaze were usually accurate, or with one small step, but downgaze appeared difficult to maintain, the patient making repeated small upward saccades even before the LED was extinguished (fig. 2).

Vertically directed saccades were accompanied by a leftward deviation (lateropulsion) whose onset corresponded with the onset of the vertical saccade so that the trajectory of the saccade was oblique (figs. 2, 3). The amplitude of the left lateropulsion was directly related to the amplitude of the vertical saccade, whether up or down (figs. 4, 5). Once the vertical saccade was completed the leftward deflection was corrected by a series of rightward saccades (fig. 2) until the eye was correctly on the target. The amplitude of the left lateropulsion was always greater on saccades from the midposition to down gaze than from up gaze to the midline.

Horizontal and vertical saccades had velocities within the normal range (Baloh et al, 1975; Bahill and Stark, 1977; Schmidt et al, 1979) but the velocities of the aberrant leftward lateropulsive saccades were less that of a normal horizontal saccade of the same amplitude.

\section{Voluntary Saccades Between Two Targets}

Noticeable difference from the previous test were discovered. Rightward saccades were well performed and only required a single small corrective saccade to reach the target (fig. 6). Leftward saccades were also performed well, but the tracings showed that the patient never quite foveated the target (fig. 6)

Vertical saccades were generally accurate requiring only one small corrective saccade reach to target. There was no difficulty in maintaining down gaze although often the patient did not quite foveate on the target, being slightly above it (fig. 7). The leftward lateropulsion accompanied only upward saccades and never downward saccades; it was corrected by multiple step refixation saccades as the eye was held in up gaze (fig. 7). The onset of the lateropulsive movement coincided with that of the upward hypometric saccade.

\section{Voluntary Saccades in the Dark}

When the central LED was turned off the eyes drifted off to the left and downwards despite command to maintain central fixation. The patient was instructed to make approximately $60^{\circ}$ movements either horizontally or vertically. Horizontal saccades of about $70^{\circ}$ were accomplished by one huge saccade or occasionally terminated with a small step. There was no difference between leftward or rightward saccades.

Vertical saccades were quite different from those directed towards targets in the light. Each large upward movement of approximately $55^{\circ}$ (fig. 8) was accompanied by a horizontal deviation about $10^{\circ}$ to the left and downward saccades showed a corresponding deviation to the right. The $X-Y$ plot shows the oblique nature of these saccades (fig. 9). Vertical saccades were of normal velocity, but the 


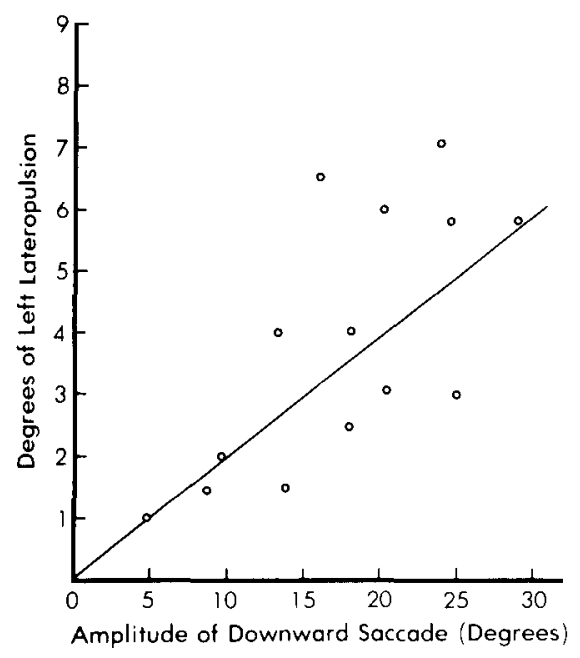

Figure 4 - Relationship of amplitude of left lateropulsion to that of downward saccades. Slope $=0.204 . \mathrm{Y}$ intercept $=$ 0.006 Correlation coefficient $=0.765$.

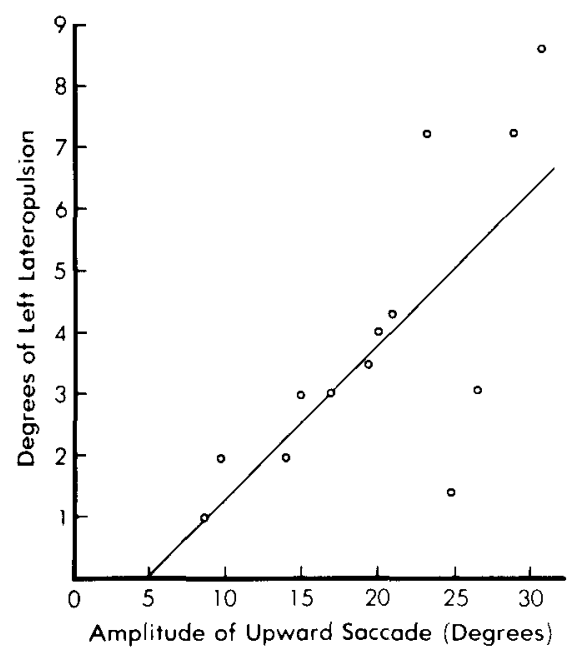

Figure 5 - Relationship of amplitude of left lateropulsion to that of upward saccades. Slope $=0.255 . \mathrm{Y}$ intercept $=$ 1.144 Correlation coefficient $=0.756$.

accompanying horizontal deviations were slower than normal horizontal saccades of the same amplitude.

\section{Pursuit}

The clinical impression of good pursuit was confirmed. The gain of the pursuit system was 0.88 horizontally and vertically for targets at $0.1 \mathrm{~Hz}$ and 0.75 horizontally and 0.71 vertically at $0.5 \mathrm{~Hz}$.

\section{DISCUSSION}

In a left Wallenberg's syndrome the anticipated ocular motor abnormalities would be overshoot of leftward saccades, hypometria of right saccades, leftward deflection of vertical saccades and tendency for the eyes to drift to the left with eyes open or closed. These defects, along with defective pursuit and a right fourth nerve palsy, were present in our patient during the original clinical examinations, but by the time the eye movement recordings were made the overshoot of leftward saccades had recovered. The vertical diplopia in our patient was due to a right fourth nerve palsy which had the classical features of right hypertropia most pronounced on gaze to the left side and on rightward head tilt. Several publications concerning Wallenberg's syndrome have remarked on the presence of vertical diplopia which was usually attributed to skew deviation (Möberg et al, 1962; Silfverskiöld, 1965; Bjerver and Silfverskiöld, 1968; Hagstrom et al, 1969; Hörnsten 1973 a, b) although perusal of the case reports indicated that the hypertropia was probably a fourth nerve palsy in many of the cases.

The possibility of an otolithic vestibular connection disturbance produced by the infarct was considered as an explanation for the vertical divergence of the eyes and the head tilt seen in our patient. However, reports of ocular tilt reaction with vestibular disease and presumed otolith dysfunction showed eye movement abnormalities quite different from a fourth nerve palsy. The Bielschowsky head tilt manoeuvre was negative (Rabinovitch et al, 1977; Halmagyi et al, 1979) and there was limited horizontal gaze (Rabinovitch et al, 1977) and a greater vertical deviation towards the side of the higher eye (Halmagyi et al, 1979) in the patients reported.

The most striking feature of our study was the task dependence of either the amplitude or the direction of the aberrant horizontal deflection (lateropulsion) which accompanied vertical saccades. Both up and down saccades were accompanied by leftward lateropulsion when saccades were made to vertically situated targets which suddenly appeared (fig. 2) but during vertical saccades between constantly illuminated targets the lateropulsion only appeared during upward saccades (fig. 7). Voluntary vertical saccades in total darkness showed the leftward deviation to accompany upward saccades, but downward saccades had an associated rightward deviation of the eyes (figs. 8, 9). Thus, the vertical eye movements in the dark were along an oblique axis rotated counter clockwise from the viewpoint of the subject. This obliquity of vertical movements suggested that the patients egocentric vertical meridian was tilted with respect to the actual gravity vector. Illusory tilt of the visual environment has been reported in patients with lateral medullary infarcts (Bjerver and Silfverskiöld, 1968; Hornsten, 1974 a). The leftward tilt of the head, which persisted to some extent after resolution of his right fourth nerve palsy, may partly be a compensatory mechanism for this illusion.

The impaired smooth pursuit initially observed in our patient is compatible with disease of the cerebellum or its brain stem connections (Zee et al, 1976). The nystagmus was not characteristic of pursuit system nystagmus due to disease of the brain stem integrator responsible for horizontal eccentric position holding (Robinson, 1975; Zee et al, 1976). The rapid recovery of the nystagmus and its original presence in the primary position of gaze make it more likely to be the result of central vestibular disease since vestibular nystagmus is usually short lived owing to central compensatory mechanisms which balance out vestibular biases. Further, the nystagmus in Wallenberg's syndrome has been noted to occur in darkness even when not present with eyes open in daylight (Hagström et al, 1969).

Vertical eye movements made towards targets did not move along a single tilted axis. Gaze changes made between continuously visible vertically placed targets revealed a tendency to direct the eye along a tilted axis when looking up, there being an added leftward deviation, but when looking down this tendency was not present so that a normal eye movement was made. The 


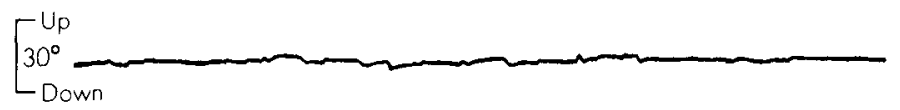

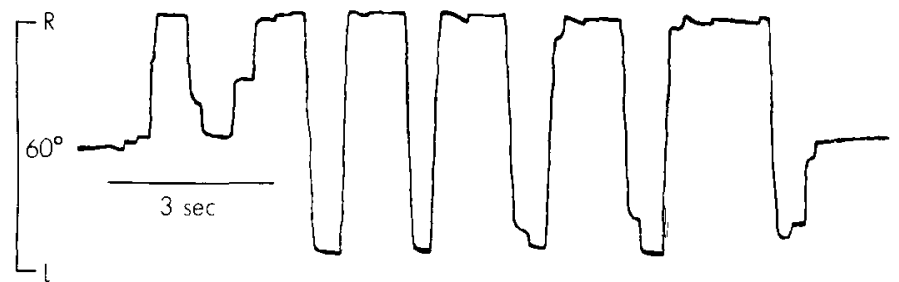

Figure 6 - Normometric voluntary horizontal saccades between continuously visible targets (lower trace). No significant associated vertical movement (upper trace).

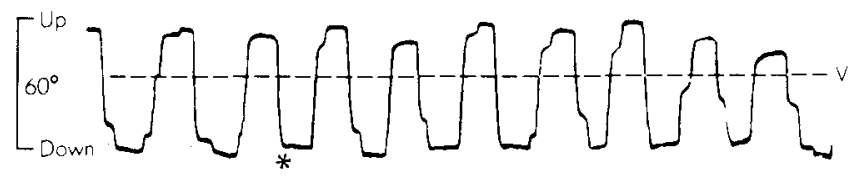

Figure 8 - Voluntary vertical saccades (upper trace) made in darkness. Upward saccades are associated with a leftward eye movement and downward saccades by a rightward movement (lower trace). $V_{0}$ and $H_{0}$ represent the true straight ahead position, the eye having drifted down and to the left in the dark. The asterisk marks the saccade photographed in fig. 9.

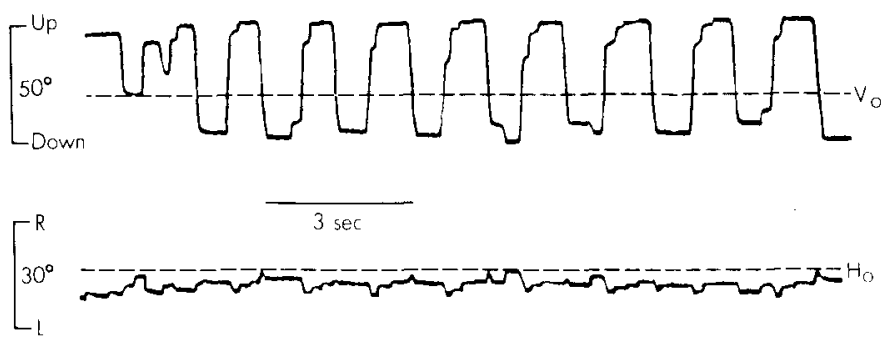

Figure 7 - Voluntary vertical saccades (upper trace) between continuously visible targets show associated left lateropulsion of the eyes (lower trace) only for upward movements. $\mathrm{H}_{O}$ and $\mathrm{V}_{O}$ represent the true straight ahead position of the eye.

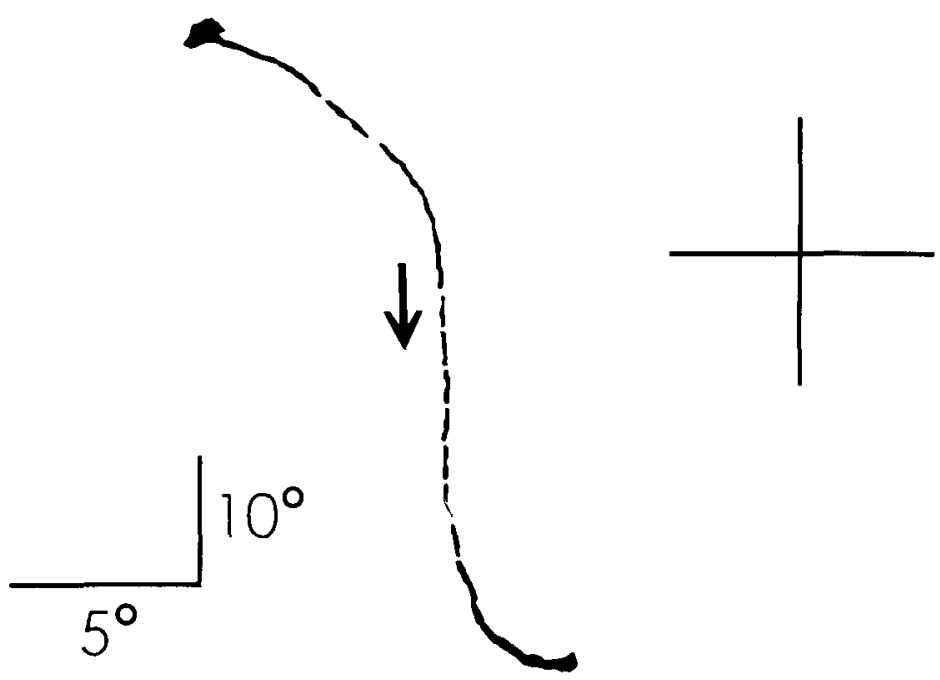

Figure $9-\mathrm{X}-\mathrm{Y}$ plot of downward saccade marked by asterisk in fig. 8 . The cross represents the true straight ahead position of the eye. The oblique trajectory of the saccade is evident. situation was further complicated for vertical eye movements triggered by the appearance of visual targets, both up and down saccades being associated with leftward lateropulsion. We attempted to determine if the leftward lateropulsions were true horizontal components of normal oblique saccades rather than non specific rapid ocular displacements produced by abnormal pulses of neural activity (Robinson, 1975). The results show the leftward deviation was not independent of the intended vertical displacement. The amplitude of lateropulsion was directly proportional to the amplitude of the vertical movement and the resulting trajectory was approximately a straight oblique saccade (figs. 4, 5). The velocity of the aberrant leftward deviation increased with amplitude just like a normal saccade but its velocity was lower than that of either a purely horizontal or vertical saccade of the same amplitude, a finding compatible with the components of normal oblique saccades (Bahill and Stark, 1977).

Our patient and others studied previously (Möberg et al, 1962; Kommerell and Hoyt, 1973) had an unconcious drift of the eyes to the side of the lesion in darkness. This, in conjunction with tests revealing errors in the assessment of target location, suggested to Kommerell and Hoyt (1973) that the leftward bias was added to the motor output "after the level where corollary discharge is evaluated". Thus the corollary discharge might not give an accurate evaluation of eye position. Current theories of saccadic eye movement control favor the hypothesis that the neural commands arriving at the saccadic pulse generator are coded by calculation of the final position in the orbit to which the eye must be brought using a corollary discharge which specifies eye position (Robinson, 1975; Zee and Robinson, 1979). If the left of center resting 
position of the eyes in the dark was thought by the patient to be his central gaze position, it is possible that when he looked at a centrally located target he believed the eye position to be right of center. Thus, a target appearing directly above or below the central fixation point would be calculated as being located either up to the left or down to the left respectively. This false perception due to inaccurate knowledge of eye position might explain the aberrant leftward directed oblique saccades observed in our subject. For the tests done in the dark knowledge of absolute eye position might be less useful and incorrect assessment of the vertical axis would therefore dominate the eye movement pattern so that all saccades would be performed along an oblique axis.

In summary, the results obtained in our patient with a left lateral medullary infarction syndrome suggest two possible mechanisms for the observed ocular motility abnormalities. There may be both faulty subjective assessment of the vertical axis and defective utilisation of information specifying eye position in calculation and coding of the target position.

\section{ACKNOWLEDGEMENTS}

We thank the Multiple Sclerosis Society of Canada for financial support and Louise May Blanchet for the manuscript.

\section{REFERENCES}

BAHILL, A.T. and STARK. L. (1977). Oblique saccadic eye movements. Independence of horizontal and vertical channels. Arch. Ophthalmol., 95: 1258-1261.

BAHILL, A.T. and TROOST, B.T. (1979). Types of saccadic eye movements. Neurology (Minn.), 29: 1150-1152.

BALOH, R.W., SILLS, A.W., KUMLEY, W.E. and HONRUBIA, V. (1975). Quantitative measurement of saccadic amplitude, duration and velocity. Neurology (Minn.), 25: 10651070.
BARRE, W. and JONES, G.M. (1965). Influence of eye lid movement upon electrooculographic recordings of vertical eye movements. Aerospace Med.. 36: 855-858.

BJERVER, D. and SILFVERSKIOLD, B.P. (1968). Lateropulsion and imbalance in Wallenberg's syndrome. Acta. Neurol. (Scand.), 44: 91-100.

COLLARD, M., EBER. A.M., COQUILLAT. G., PHILIPPOTT, J. and ROHMER, F. (1975). Laterogyrie spasmodique du regard au cours d'un syndrome de Wallenberg. Rev. Otoneuroophtal., 47: 195-198.

COLLEWIJN, H., VAN DER MARK, F. and JANSEN, T.C. (1975). Precise recording of human eye movements. Vision Res., 15: 447450.

CURRIER, R.D. (1969). Syndromes of the medulla oblongata. In: Handbook of clinical neurology. Amsterdam. North Holland Publishing Company. (VINKEN. P.J. and BRUYN, G.W., eds.) 2. pp 217-237.

DAROFF, R.B., HOYT, W.F.. SANDERS, M.D. and NELSON. E.R. (1968). Gaze evoked eyelid and ocular nystagmus inhibited by the near reflex: unusual ocular motor phenomena in a lateral medullary syndrome. J. Neurol. Neurosurg. Psychiat., 31: 362367.

FISHER, C.M.. KARNES, W.E. and KUBIK. C.S. (1961). Lateral medullary inlarction - the pattern of vascular occlusion. J. Neuropath. Exp. Neurol., 20: 323-379.

GILLILAN. L.A. (1964). The correlation of the blood supply to the human brain stem with clinical brain stem lesions. J. Neuropath. Exp. Neurcl., 23: 78-108.

HAGSTROM, L., HORNSTEN, G. and SILFVERSKIOLD, B.P. (1969). Oculostatic and visual phenomena occurring in association with Wallenberg's syndrome. Acta Neurol. (Scand.), 45: 568-582.

HALMAGYI, G.M., GRESTY, M.A.. GIBSON, W.P.R. (1979). Ocular tilt reaction with peripheral vestibular lesion. Ann. Neurol., 6: 80-83

HAMANN, K.U. (1979). Systematisch Abweichung sakkadischer Augenbewegungen beim Wallenberg-Syndrom. Ophthalmologica (Basel), 178: 373-380.

HORNSTEN, G. (1974a). Wallenberg's syndrome. Part 1. General symptomatology with special reference to visual disturbances and imbalance. Acta Neurol. (Scand.), 50: 434-446.
HORNSTEN, G. (1974b). Wallenberg's syndrome. Part II. Oculomotor and oculostatic disturbances. Acta Neurol. (Scand.), 50: 447468.

HOYT, W.F. and FRISEN, L. (1975), Supranuclear ocular motor control. Some clinical considerations 1974. In: Basic mechanisms of ocular motility and their clinical implications. Oxford, England. Pergamon Press. (BACH-Y-RITA. P.. IENNERSTRANI). (i., cds.) pp 379-392.

KOMMERELL, G. and HOYT, W.F. (1973). Lateropulsion of saccadic eye movements. Electrooculographic studies in a patient with Wallenberg's syndrome. Arch. Neurol., 28 : 313-318.

MOBERG, A., PREBER. L.. SILFVERSKIOLD. B.P. and VALLBO, J. (1962). Imbalance. nystagmus and diplopia in Wallenberg's syndrome. Clinical analysis of a case and post-mortem examination. Acta Otolaryngol. (Scand.). 55: 269-2×2.

RABINOVITCH, H.E., SHARPE, J,A, and SYLVESTER. T.O. (1977). The ocular tilt reaction. A paroxysmal dyskinesia associated with elliptical nystagmus. Arch. Ophtha!mol.. 95: 1395-1398

ROBINSON, D.A. (1963). A method of measuring eye movement using a scleral search coil in a magnetic field. I.E.E.E. Trans. Biomed. Electron., B.M.E., 10: 137145.

ROBINSON. D.A. (1975). Oculomotor control signals. In: Basic mechanisms of ocular motility and their clinical implications. Oxford, England, Pergamon Press. (BACHY-RITA, P.. LENNERSTRAND, G., eds.) pp 337-374.

SCHMIDT, D., ABEL, L.A.. DELL'OSSO, L.F. and DAROFF. R.B. (1979). Saccadic velocity characteristics: Intrinsic variability and fatigue. Aviat. Space Environ. Med.. 50: 393-395.

SILFVERSK IOL.D. B.P. (1965). Skew deviation in Wallenberg's syndrome. Acta. Neurol. (Scand.). 41: 381-386

ZEE, D.S. and ROBINSON, D.A. (1979). A hypothetical explanation of saccadic oscillations. Ann. Neurol., 5: 405-414.

ZEE, D.S., YEE, R.D., COGAN, D.G. ROBINSON, D.A. and ENGEL. W.K. (1976). Ocular motor abnormalities in hereditary cerebellar ataxia. Brain, 99: 207 234. 